\title{
Investigations of surface morphology and microrelief of GaAs single crystals by complementary methods
}

\author{
D. Źymierska a , J. Auleytner ${ }^{\mathrm{a}}$ and N. Dmitruk \\ ${ }^{a}$ Institute of Physics, Polish Academy of Sciences, Warsaw, Poland \\ al. Lotników 32/46, 02-668 \\ tel.: (48) (22) 843-60-34 or 843-70-01 ext. 3304 \\ fax: (48) (22) 843-09-26 \\ e-mail: zymier@ifpan.edu.pl \\ ${ }^{b}$ Institute Semiconductor of Physics, National Academy of Sciences of Ukraine, \\ Prosp. Nauki 45, 03028, Kiev, Ukraine \\ Tel: +380442656486 \\ Fax: +380442658342 \\ E-mail:nicola@dep39.semicond.kiev.ua
}

\begin{abstract}
The paper presents the study of morphology and roughness of (100) surfaces of GaAs single crystals grown by the Czochralski method. The surfaces were prepared in a different way: mechanical polishing, chemomechanical polishing, mechanical grinding, wet polishing etching, anisotropic etching. The X-ray grazing incidence reflectivity, atomic force microscopy, scanning tunneling microscopy, optical specular reflection, and profilometric methods were complementary used. The application of these methods allowed to reveal the details of differences in the surface morphology varied with the way of its preparation.
\end{abstract}

Keywords: GaAs, surface roughness, X-ray reflectometry, optical reflection, atomic force microscopy, profilometry

Paper received 21.06.00; revised manuscript received 10.09.00; accepted for publication 12.12.00.

\section{Introduction}

The present paper is devoted to the research of the surfaces of GaAs single crystals as it is a material of great technological importance, especially in many applications and production of optoelectronic devices such as semiconductor photodiodes and lasers, and the quality of the surface influences parameters of a device, e.g., large surface roughness decreases the luminescence efficiency of it. Very smooth surfaces can be used, e.g., as substrates for high electron mobility transistors (HEMT) and for preparation of different structures as well as for epitaxy.

The aim of the present paper is to state an influence of different surface preparation on their roughness and morphology. The studied surfaces of GaAs single crystals were prepared in several different ways (mechanical polishing, chemomechanical polishing, mechanical grinding, wet etching, anisotropic etching) to obtain distinguished surface profiles and roughness, micro-relief with surface irregularities $\leq 10 \mathrm{~nm}$, and macro-relief with irregularities $>10 \mathrm{~nm}$. The former surfaces were investigated by means of grazing incidence $\mathrm{X}$-ray reflectometry
(GIXR), scanning tunneling microscopy (STM) and atomic force microscopy (AFM) which are related to the same nanometer scale. X-ray reflectometry provides average roughness data from the large surfaces [1-6], and atomic force microscopy determines a local surface roughness and is very useful in surface morphology research (see, for example [7]), the latter surfaces were studied by using the optical specular reflection and profilometry.

\section{Experimental}

\subsection{Samples preparation}

Single crystals of semi-insulating and $n$-GaAs with surface orientation (100) were grown by Czochralski method. The resistivity of semi-insulating GaAs single crystal (sample GaAs-1) was equal to about $10^{6} \Omega \mathrm{cm}$. The carrier concentration of $n$-GaAs was equal to about $10^{18} \mathrm{~cm}^{-3}$ for one single crystal (sample GaAs-2), and to about $10^{16} \mathrm{~cm}^{-3}$ for other ones (samples GaAs-3 and GaAs-4). For each surface a different treatment was used. 


\section{D. Źymierska et al.: Investigations of surface morphology and microrelief ...}

One side of sample GaAs-1 (surface B), both sides of sample GaAs-2 (surfaces C and D), and one side of sample GaAs-3 (surface E) were chemomechanically polished with $\mathrm{NaOCl}$ particles in suspension in water/glycerol mixture, then cleaned by means of threefold boiling ( $1 \mathrm{~min}$. each) in $\mathrm{CCl}_{4}$ and acetone, and finally rinsed thoroughly in distilled water. Surfaces with the very small micro-relief were obtained in this way. Other sides of samples GaAs-1 (surface A) and GaAs-3 (surface F) were mechanically grinded. Both sides of sample GaAs-4 were chemically wet etched in polishing mixture of $\mathrm{Br}_{2}+$ dioxan + $\mathrm{HCl}$ at temperature equal to $20^{\circ} \mathrm{C}$ during 1 min (surfaces $\mathrm{G}$ and $\mathrm{H}$ ). Then surface $\mathrm{G}$ was anisotropically etched in concentrated $\mathrm{HNO}_{3}$ acid at temperature $25^{\circ} \mathrm{C}$ for $2 \mathrm{~s}$ and surface $\mathrm{H}$ - in concentrated $\mathrm{HNO}_{3}$ acid at temperature $20^{\circ} \mathrm{C}$ for $15 \mathrm{~s}$. The last treatment creates a macro-relief of dendritic type. The data concerning samples and preparation of the surfaces studied are given in Table 1 .

\subsection{Profilometry}

The geometric parameters of the relief were estimated using Dektak-II profilometer with the submicron tip radius.

\subsection{Grazing incidence $X$-ray reflectivity}

The X-ray reflectivity at grazing incidence (GIXR) was measured with the $\mathrm{CuKa}_{1}(\lambda=0.1541 \mathrm{~nm})$ radiation by high resolution Philips MRD equipped with the Bartels monochromator. In this way, a highly monochromatic $\mathrm{X}$-ray beam is obtained $\left(\Delta \lambda / \lambda=6.9 \times 10^{-5}\right)$ with a low divergence $(\Delta \Theta=12$ arcsec $)$. The intensity of the beam reflected from investigated surface was measured with the proportional counter. The data were collected in classical $\Theta: 2 \Theta$ scan.

\subsection{Optical specular reflection}

The optical specular reflection spectra were measured at room temperature in the spectral range $\lambda=(4-10.5) \times$ $\times 10^{2} \mathrm{~nm}$ by a MDR-3 spectrometer for different incidence angles with both the suitable attachment and the $\mathrm{Al}$ mirror as a standard. The anisotropically etched surfaces $\mathrm{G}$ and $\mathrm{H}$ with a macro-relief were studied using a UR-10 spectrometer within the spectral range $\lambda=(2.0-20.0) \mu \mathrm{m}$ for near normal incidence $\left(\varphi=7^{\circ}\right)$.

Table 1. Characterization of GaAs single crystal samples and their surfaces

\begin{tabular}{|c|c|c|c|c|c|c|c|}
\hline Sample & $\begin{array}{c}\text { Type of } \\
\text { conductivity }\end{array}$ & $\begin{array}{l}\text { Resistivity } \\
\Omega \mathrm{cm}\end{array}$ & $\begin{array}{c}\text { Carrier } \\
\text { concentration } \\
\mathrm{cm}^{-3}\end{array}$ & Surface & $\begin{array}{c}\text { Surface } \\
\text { orientation }\end{array}$ & $\begin{array}{c}\text { Surface } \\
\text { treatment }\end{array}$ & $\begin{array}{l}\text { Character } \\
\text { of the } \\
\text { surface }\end{array}$ \\
\hline \multirow[t]{2}{*}{ GaAs-1 } & \multirow[t]{2}{*}{$\begin{array}{c}\text { semi- } \\
\text { insulating }\end{array}$} & \multirow[t]{2}{*}{$10^{6}$} & \multirow[t]{2}{*}{-} & A & \multirow{8}{*}{ (100) } & $\begin{array}{c}\text { mechanical } \\
\text { grinding }\end{array}$ & grinded \\
\hline & & & & B & & $\begin{array}{c}\text { chemo } \\
\text { dynamic. } \\
\text { polishing }\end{array}$ & $\begin{array}{l}\text { micro- } \\
\text { relief }\end{array}$ \\
\hline \multirow[t]{2}{*}{$\overline{\mathrm{GaAs}-2}$} & \multirow{6}{*}{$\begin{array}{l}n \text {-semi- } \\
\text { conducting }\end{array}$} & \multirow[t]{2}{*}{-} & \multirow[t]{2}{*}{$10^{18}$} & $\mathrm{C}$ & & $\begin{array}{l}\text { chemo } \\
\text { dynamic. } \\
\text { polishing }\end{array}$ & $\begin{array}{l}\text { micro- } \\
\text { relief }\end{array}$ \\
\hline & & & & $\mathrm{D}$ & & $\begin{array}{c}\text { chemical } \\
\text { etching }\end{array}$ & $\begin{array}{l}\text { macro- } \\
\text { relief }\end{array}$ \\
\hline \multirow[t]{2}{*}{ GaAs-3 } & & \multirow[t]{4}{*}{-} & \multirow{4}{*}{$10^{16}$} & $\mathrm{E}$ & & $\begin{array}{l}\text { chemo } \\
\text { dynamic. } \\
\text { polishing }\end{array}$ & $\begin{array}{l}\text { micro- } \\
\text { relief }\end{array}$ \\
\hline & & & & $\mathrm{F}$ & & $\begin{array}{c}\text { mechanical } \\
\text { grinding }\end{array}$ & grinded \\
\hline \multirow[t]{2}{*}{ GaAs-4 } & & & & $\mathrm{G}$ & & $\begin{array}{c}\text { short } \\
\text { anisotropic } \\
\text { etching }\end{array}$ & $\begin{array}{l}\text { micro- } \\
\text { relief }\end{array}$ \\
\hline & & & & $\mathrm{H}$ & & $\begin{array}{c}\text { long } \\
\text { anisotropic } \\
\text { etching }\end{array}$ & $\begin{array}{l}\text { dendritic } \\
\text { macro- } \\
\text { relief }\end{array}$ \\
\hline
\end{tabular}

In the present paper the surface irregularities $\leq 10 \mathrm{~nm}$ are called a micro-relief, and those $>>10 \mathrm{~nm}-$ a macro-relief. 


\section{D. Źymierska et al.: Investigations of surface morphology and microrelief ...}

\subsection{Atomic force microscopy and scanning tunneling microscopy}

Surface morphology was investigated by means of atomic force microscopy (AFM) as well as by scanning tunneling microscopy (STM). In the research a NanoScope «Dimension 3000 (Digital Instruments)» with $\mathrm{Si}_{3} \mathrm{~N}_{4}$ tip, and a scanning tunneling microscope with a tungsten tip electrochemically pointed were used, respectively.

\section{Results}

\subsection{Surface profiles}

The surface profile functions $S(x)$ for studied GaAs single crystals were obtained from profile measurements using profilometer or stylus instrument. The function $S(x)$ was used to calculate the surface-autocorrelation function $(\mathrm{ACF})$. In the present paper only isotropic surfaces are investigated, therefore ACF can be described by one argument $x$ and written as $G(x)$ [8-10]. In a one-dimensional model:

$G(x)=\delta^{2} \cdot \exp \left[-(x / L)^{2 h}\right]$,

where $\mathrm{d}$ is the the root-mean-square (RMS) value of the surface roughness, $x$ is a distance between two points in $x$, $y$ plane for which the height-height correlation function is cosidered, $L$ is a roughness correlation length and $h$ is a roughness exponent taking values from 0 for a very jagged surface to 1 for smooth hills and valleys at surface. For $h=1$ the correlation function decays like a Gaussian.

According to the statistical theory the value of $\delta$ may be determined by the value of $G(0)$

$\delta=[G(0)]^{1 / 2}$,

and the correlation length $L$ may be obtained from ACF by means of the formulae:
$L_{1}=2 \sqrt{2} \pi^{-1 / 2} \delta^{-4} \int_{0}^{\infty}[G(x)]^{2} d x$,

$L_{2}=\delta\left[-2 / G^{\prime \prime}(0)\right]^{1 / 2}$,

where the value of $L_{l}$ characterises a long scale roughness while the value of $L_{2}$ refers mainly to a short-scale case, and for Gaussian surfaces $L_{1}=L_{2}$.

From Eq. (1) we obtain:

$\ln (\ln [G(0) / G(x)])=2 h \cdot \ln (x / L)$,

i.e. the scaling exponent $h$ can be determined from the slope of this linear dependence (4) (see Fig.1). The obtained surface parameters are given in Table 2.

\subsection{Micro-relief from $X$-ray measurements}

The results of X-ray reflectivity measured as a function of the grazing angle $\Theta_{1}$ are shown in Fig. 2. For an intrepretation of the experimental data the calculated reflectivity profiles were used. The theoretical calculations were performed in the way presented in the previous paper [11] which was based on the Fresnel theory [8] and classic paper of Parratt [12]. To the Fresnel equations valid for a smooth surface the additional damping factor, so called scattering coefficient $g$ for reflectivity from a rough surface was introduced, thus the reflectivity from a rough surface with a relief can be written as

$R_{\mathrm{rel}}=R_{\mathrm{fl}} \gamma\left(\lambda, \Theta_{1}, \delta\right)$,

where $R_{\mathrm{fl}}$ is the reflectivity from a smooth (flat) surface, $\lambda$ is the wavelength of incident $\mathrm{X}$-ray radiation, $\Theta_{1}$ is the angle of grazing incidence.

The coefficient $\mathrm{g}$ has the following form for a Gaussian distribution of the surface roughness $[1,9,13]$ :

$\gamma=\exp \left(-4 k_{1}^{2} \delta^{2} \sin ^{2} \Theta_{1}\right)$,

Table 2. Comparison of surface parameters obtained by applied methods

\begin{tabular}{c|c|c|c|c|c|c|c|c}
\hline \hline \multirow{2}{*}{ Surface } & GIXR & AFM & \multicolumn{2}{|c|}{ Optical reflection } & \multicolumn{5}{|c}{ Profilometry } \\
\cline { 2 - 9 } & RMS $\delta, \mathrm{nm}$ & $\mathrm{RMS} \delta, \mathrm{nm}$ & $H_{1}, \mathrm{~nm}$ & $H_{2}, \mathrm{~nm}$ & $2 h$ & $\delta, \mathrm{nm}$ & $H=4 \delta, \mathrm{nm}$ & $L, \mathrm{~nm}$ \\
\hline $\mathrm{A}$ & & & 180 & 110 & 1.6 & 38.7 & 155 & 226 \\
\hline $\mathrm{B}$ & $4.1 \pm 0.9$ & & & & & & & \\
\hline $\mathrm{C}$ & $2.2 \pm 0.5$ & 2.5 & & & & & & \\
\hline $\mathrm{D}$ & & & 179 & 84 & 1.5 & 38.0 & 152 & 284 \\
\hline $\mathrm{E}$ & $5.4 \pm 1.2$ & & & & & & & \\
\hline $\mathrm{F}$ & & & 301 & 98 & & & & \\
\hline $\mathrm{G}$ & & 10 & & & & & & \\
\hline $\mathrm{H}$ & & $1000-2000$ & & & & & & \\
\hline \hline
\end{tabular}




\section{D. Źymierska et al.: Investigations of surface morphology and microrelief ...}

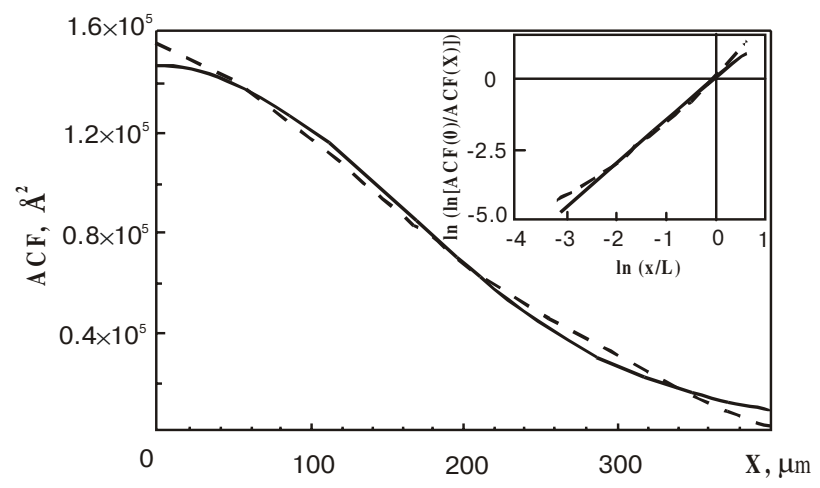

Fig. 1. The surface autocorrelation function (ACF) for surface A calculated from the pofilometric data; Gaussian approximation is indicated by solid line. The insert shows the dependence of $\ln \ln [G(0) / G(x)]$ on $\ln (x / L)$ (dashed line) and its straigh-line approximation (solid line).

where $k_{1}$ is the wave vector of the incident $X$-ray radiation.

By adjusting the theoretical reflectivity profiles (full lines) (see Fig. 2) to the measured curves (triangles for surface $\mathrm{B}$, squares for surface $\mathrm{C}$ and circles for surface $\mathrm{E}$, respectively) the values of surface micro-roughness were obtained. In the ideal case of non-absorbing solid with perfectly flat and smooth surface, the grazing incidence $\mathrm{X}$-ray reflectivity becomes unity below critical angle $\Theta_{c}$ and drops to zero for $\Theta_{1}=1.5 \Theta_{c}$ and this decay is approximately proportional to $\Theta_{1}^{-4}$, so fitting to the experimental data was performed for angles of incidence smaller than $0.5^{\circ}$. The best fitting for $\mathrm{CuKa}_{1}$ radiation was obtained with the assumption that studied surfaces with micro-relief are Gaussian ones $(h=1.0)$ and for the following RMS surface roughness values: for surface B: $\delta=$ $=(4.1 \pm 0.9) \mathrm{nm}$, for surface $\mathrm{C}: \delta=(2.2 \pm 0.5) \mathrm{nm}$, and for surface $\mathrm{E}: \delta=(5.4 \pm 1.2) \mathrm{nm}$. It was estimated that in the case considered the fitting of the simulated reflectivities to the measured X-ray data was done with precision of $25 \%$. The surface irregularities of other surfaces (with macro-relief) were too high for X-ray studies.

\subsection{Macro-relief from optical measurements}

The results of the optical specular near-normal reflection measurements are presented in Fig. 3. According to formulae (5) and (6) the value of logarithm of the relative reflection coefficient from a rough surface, $R^{\prime}=R_{\mathrm{rel}} / R_{\mathrm{fl}}$, where $R_{\text {rel }}$ is the reflection coefficient of a macro-relief and $R_{\mathrm{fl}}$ - the reflection coefficient of the so-called «flat» surface, is linear versus $\lambda^{-2}$ with $\lambda$ being the wavelength of the incident optical radiation.

A slope of $\ln \left(R^{\prime}\right)$ line depends on the square of RMS value of the surface roughness. In Fig. 3 this dependence for surfaces A, D and F is shown. In these cases broken lines are registered. Similar dependence of $R^{\prime}$ on $\lambda^{-2}$ was found for InP surfaces [14]. Two different slopes of the

SQO, 3(4), 2000
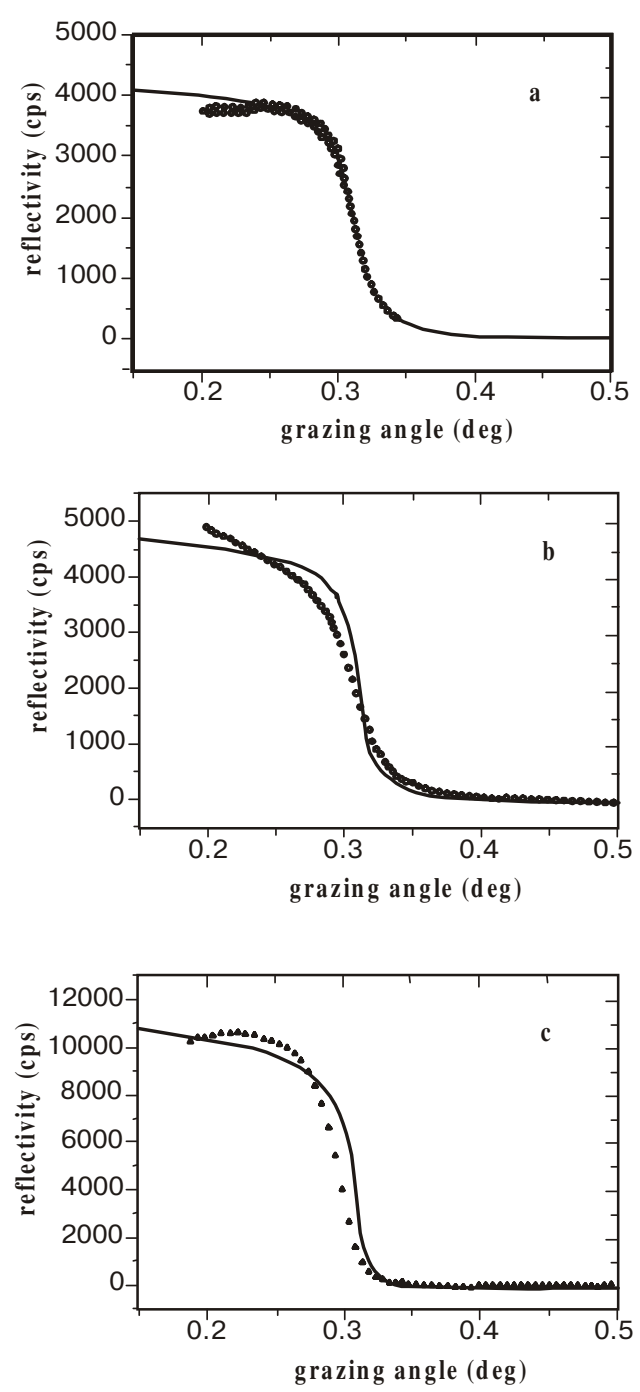

Fig. 2. The fitting of calculated reflectivity profiles (solid lines) to experimental grazing incidence $\mathrm{X}$-ray reflectivity curves measured with $\mathrm{CuKa}_{1}$ radiation from the chemomechanically polished surfaces of GaAs single crystals with the micro-relief studied: (a) - for surface C (squares), (b) - for surface E (circles), and (c) - for surface B (triangles). The obtained RMS surface micro-roughness values are given in Table 2.

obtained broken line was interpreted as the presence of two components in the relief. We adopt the same interpretation in the present paper. In other words, from two different slopes of the broken line we deduced that there are two different shapes of surface irregularities of the macro-relief being $180 \mathrm{~nm}$ and $110 \mathrm{~nm}$ high for surface A (Fig. 3a), $179 \mathrm{~nm}$ and $84 \mathrm{~nm}$ high for surface D (Fig. 3b) and $301 \mathrm{~nm}$ and $98 \mathrm{~nm}$ high for surface F (Fig. 3c), respectively.

The comparison of the results obtained by means of different methods applied complementary is given in Table 2. 


\section{D. Źymierska et al.: Investigations of surface morphology and microrelief ...}

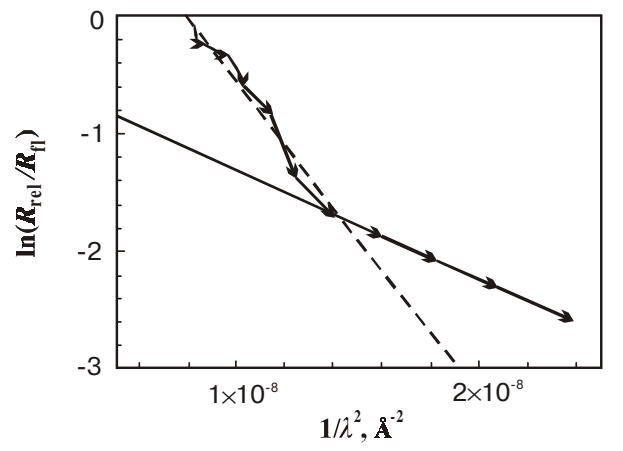

b)

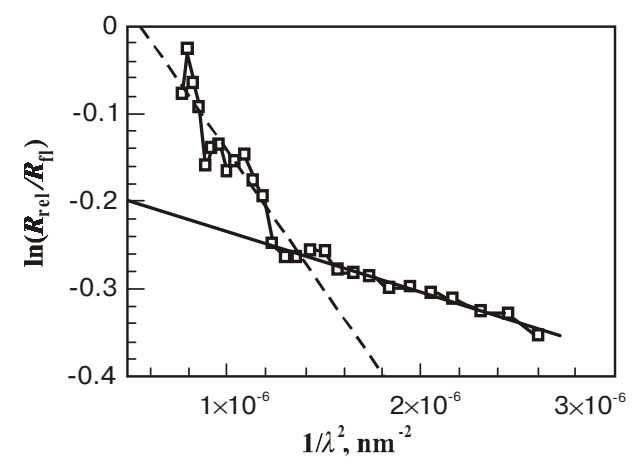

c)

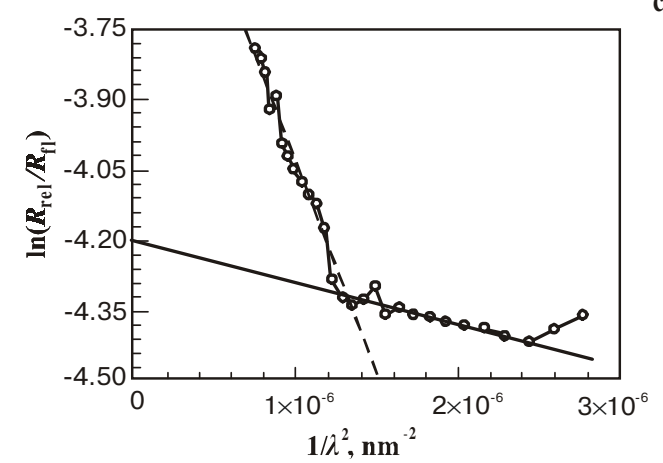

Fig. 3. Value of the logarithm of relative reflection coefficient $\ln \left(R^{\prime}\right)$ versus $1 / 1^{2}$ with 1 being the wavelength of incident optical radiation: (a) - for grinded surface A (triangles), (b) - for polished surface D (squares) and (c) - for grinded surface F (circles).

\subsection{Atomic force microscopy}

The result of the surface roughness obtained by X-ray reflectometry for surface $\mathrm{C}$ with the micro-relief was confirmed by means of AFM method. In Fig. 4 the threedimensional AFM image of randomly selected area of $5 \times 5 \mu \mathrm{m}^{2}$ taken in the tapping mode by measuring the height of the modulation current of the cantilever in $z$ direction is presented. In Fig. 5a the AFM surface profile taken along a line is given, and on Fig. $5 \mathrm{~b}$ the histogram of heights relatively some dippest one is presented. From this histogram the most probable absolute RMS height can be obtained, i.e. $H=10 \mathrm{~nm}$.

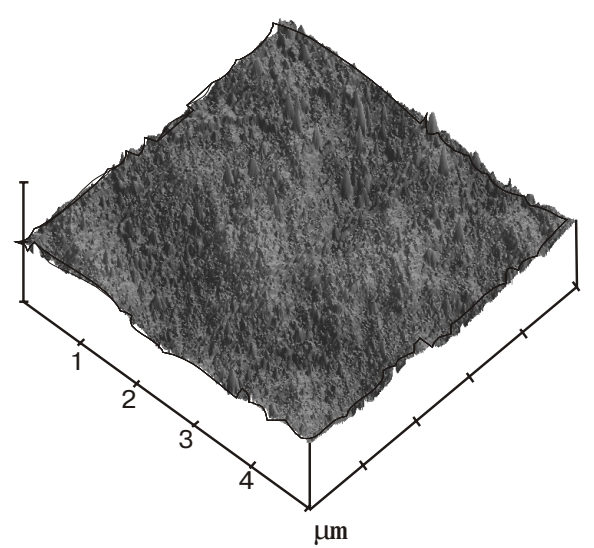

Fig. 4. The three-dimensional AFM image of randomly selected area of $5 \times 5 \mu \mathrm{m}^{2}$ of GaAs surface $\mathrm{C}$ with micro-relief taken in the tapping mode by measuring the velue of the modulation current of the cantilever in $z$ direction.

Because this surface is similar to Gaussian, the relation $\mathrm{H}=4 \cdot \delta$ takes place [10], and we have got: $\delta=2.5 \mathrm{~nm}$. The obtained RMS value of surface roughness is in excelent agreement with the X-ray value $2.2 \mathrm{~nm}$ (see Table 2).

Local images $8 \times 8 \mathrm{~nm}^{2}$ in STM and $20 \times 20 \mathrm{~nm}^{2}$ in AFM of anisotropically etched GaAs surfaces $\mathrm{G}$ and $\mathrm{H}$ are presented in Figs. 6 and 7, respectively. It is seen that

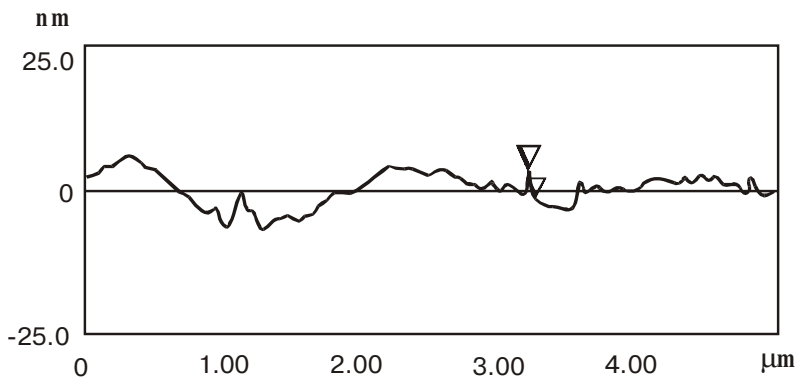

Fig. 5a. Surface profile taken along a line of AFM image from the GaAs surface, the three-dimensional AFM image of which is shown in Fig. 4.

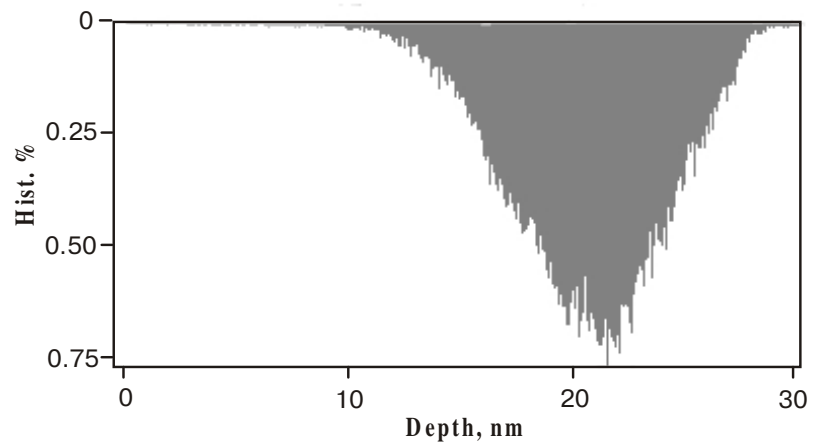

Fig. 5b. Histogram of relative heights of this surface microrelief.

$S Q O, 3(4), 2000$ 


\section{D. Źymierska et al.: Investigations of surface morphology and microrelief ...}

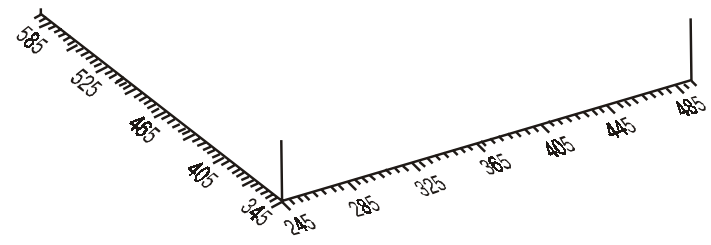

Fig. 6. The STM picture of the area of $8 \times 8 \mathrm{~nm}^{2}$ of the initial stage of anisotropically etched GaAs surface $\mathrm{G}$ (anisotropic etchant concentrated $\mathrm{HNO}_{3}$, temperature $T=25^{\circ} \mathrm{C}$, and etching duration $t=2 \mathrm{~s})$.

after short anisotropic etching (duration $2 \mathrm{~s}$ ) the surface has a form of smooth hills and valleys with height and foot of about $10 \mathrm{~nm}$. After long etching (15 s) in the same concentrated $\mathrm{HNO}_{3}$ acid, the height of the surface roughness in the form of pyramids reaches approximately $1-2 \mu \mathrm{m}$.

\section{Discussion}

The determination of the surface roughness infrinsic to different surfaces of the GaAs single crystals obtained by the Czochralski method has been presented. The surfaces were prepared in different ways. Surfaces subjected to chemomechanical polishing and short wet anisotropic etching ( $2 \mathrm{~s})$ revealed the micro-relief with the surface roughness $\leq 10 \mathrm{~nm}$, and those subjected to mechanical grinding and mechanical polishing resulted in the macrorelief with surface irregularities $>10 \mathrm{~nm}$. The surface $\mathrm{H}$ anisotropically etched for a long time $(15 \mathrm{~s})$ revealed the macro-relief of the dendritic morphology. The system of

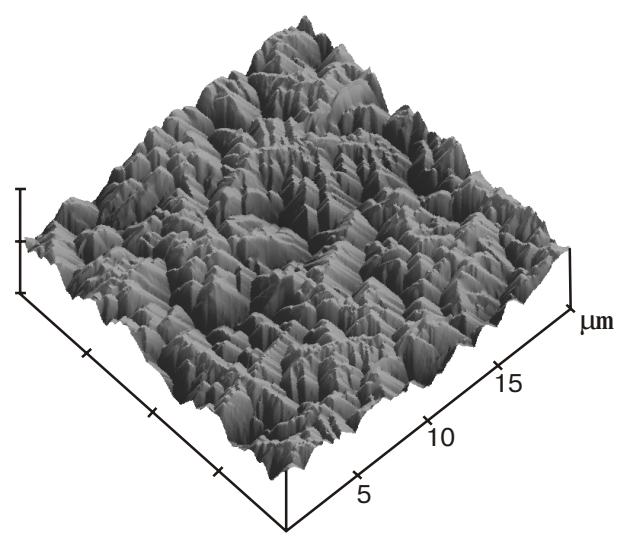

Fig. 7. The three-dimensional AFM image of randomly selected area of $20 \times 20 \mu \mathrm{m}^{2}$ of anisotropically etched GaAs surface $\mathrm{H}$ (anisotropic etchant - concentrated $\mathrm{HNO}_{3}$, temperature $T=20^{\circ} \mathrm{C}$, and etching duration $t=15 \mathrm{~s}$ ) taken in the same mode as in Fig. 4. convex pyramids with the height of about $1-2 \mu \mathrm{m}$ and with comparative size of planar foot is seen in Fig. 7. The parameters of the dendritic relief were selected empirically to ensure necessary selectivity of reflection in the wide spectral region from 0.3 to $25 \mu \mathrm{m}$. The dendritic macro-relief is especially attractive for photoelectronic applications [15].

Because the range of surface roughness which can be examined depends on the wavelength of used radiation, $\mathrm{X}$-ray and optical techniques were used complementary. The optical measurements were carried out in the spectral range $\lambda=(4-10.5) \cdot 10^{2} \mathrm{~nm}$, and X-ray measurements were performed with $\mathrm{CuKa}_{1}$ radiation $(\lambda=0.1541 \mathrm{~nm})$. The optical measurements relate to the surface profile (macro-relief) at micrometer scale, and X-ray ones relate to the detailed micro-irregularities (micro-relief) at the nanometer scale.

The independent information about the macro-relief and the micro-relief surface roughness was obtained by profilometry and AFM, respectively. Especially good correspondence of the X-ray results with those of AFM was found for chemomechanically polished surface C (see Figs 2a, 4 and 5).

Methods applied in the present study give a good characterization of surface morphology, therefore the results of these investigations can be used, in our opinion, for practical purposes.

\section{Conclusions}

From the present studies, performed on the surfaces of GaAs single crystals, it follows that the surface morphology depends on the applied method of its preparation. The application of the complementary methods of research allowed to reveal details concerning differences in morphology of investigated surfaces.

It appeared that optical and profilometric methods allow to show the surface roughness $>>10 \mathrm{~nm}$, and $\mathrm{X}$ ray and AFM techniques - the surface roughness $\leq 10 \mathrm{~nm}$. In the case of chemomechanically polished smooth surface $\mathrm{C}$ the results obtained by means of GIXR and AFM methods are almost the same.

The comparison of the results obtained by different methods are given in Table 2.

Real relief of semiconductor surface is being a superposition of macroroughness and a small ripple (microrelief); that is why the optical and X-ray reflection are complementary methods.

\section{Acknowledgments}

We would like to thank Mr. J. Domagala from the Institute of Physics of the Polish Academy of Sciences (Warsaw) for cooperation in X-ray experiments as well as Dr. A.A. Marchenko from the Institute of Physics of the National Academy of Sciences of Ukraine (Kiev) for performing STM measurements. 


\section{D. Źymierska et al.: Investigations of surface morphology and microrelief ...}

\section{References}

1. S.K. Sinha, E. B. Sirota, S. Garoff, H. B. Stanley, X-ray and neutron scattering from rough surfaces // Phys. Rev. B. 38, pp. 2297-2311 (1988).

2. D.K. Bowen, B. K. Tanner, Characterization of engineering surfaces by grazing-incidence X-ray reflectivity // Nanotechnology. 4, pp 175-182 (1993).

3. W. Weber, B. Lengeler, Diffuse scattering of hard X-rays from rough surfaces // Phys. Rev. B. 46, pp. 7953-7956 (1993)

4. O.A. Sakata, Y. Nikulin, H. Hashizume, X-ray evaluation of microroughness of mechanochemically polished silicon surfaces // Jpn. J. Appl. Phys. 32, pp. L616-L619 (1993).

5. D.K. Bowen, M. Wormington, Grazing incidence X-ray characterization of materials // Advances in X-Ray Analysis. 36, pp. 171-184 (1993).

6. D. Źymierska, J. Auleytner, Application of X-rays to the Study of the Surface Roughness // Cryst. Res. Technol. 32, pp. 135-141 (1997).

7. J.A. De Rose, R. M. Leblanc, Scanning tunneling and atomic force microscopy studies of Langmuir-Blodgett films // Surf. Sci. rep. 22, pp. 73-126 (1995).
8. P. Beckmann, A. Spizzichino, The Scattering of Electromagnetic Waves from Rough Surfaces, Pergamon Press, Oxford 492 p. (1963).

9. B.B. Mandelbrot, The Fractal Geometry of Nature, Freeman, New York 1982.

10. G. Rasigni, M. Rasigni, J. Palmari, C. Dussert, F. Varnier, A. Llebaria, Statistical parameters for random and pseudorandom rough surfaces // J. Opt. Soc. Am. A 5, N1, pp. 99103 (1988).

11. D. Źymierska, Determination of Surface Roughness by Grazing Incidence X-ray Reflectivity, // Acta Phys Polon. A. 89, pp. 347-352 (1996).

12. L.G. Parratt, Surface Studies of Solids by Total Reflection of X-Rays // Phys. Rev. 95, pp. 359-369 (1954).

13. S. K. Sinha, Surface Roughness by X-ray and Neutron Scattering Methods // Acta Phys. Polon. A. 89, pp. 219-234 (1996).

14. N.L. Dmitruk, T. R.Barlas, E.V. Basiuk, Preparation, morpholy and physical properties of microrelief InP surfaces // Solar Energy Mater. Solar Cells. 31, pp. 371-382 (1993).

15. N.L. Dmitruk, V.G. Litovchenko, S.V. Mamikin, Photo-emission of microrelief semiconductor surfaces with semitransparent Au films // J. Vac. Sci. Technol. B. 13, N2, pp. 445447 (1995). 